\title{
Season-dependent associations of circadian rhythm-regulating loci (CRY1, CRY2 and MTNR1B) and glucose homeostasis: the GLACIER Study
}

\author{
Frida Renström • Robert W. Koivula • Tibor V. Varga • \\ Göran Hallmans • Hindrik Mulder • Jose C. Florez • \\ Frank B. Hu • Paul W. Franks
}

Received: 5 December 2014 / Accepted: 2 February 2015 / Published online: 24 February 2015

(C) Springer-Verlag Berlin Heidelberg 2015

\begin{abstract}
Aims/hypothesis The association of single nucleotide polymorphisms (SNPs) proximal to $C R Y 2$ and MTNR1B with fasting glucose is well established. $C R Y 1 / 2$ and MTNR1B encode proteins that regulate circadian rhythmicity and influence
\end{abstract}

F. Renström $(\triangle) \cdot$ R. W. Koivula $\cdot$ T. V. Varga $\cdot$ P. W. Franks Genetic and Molecular Epidemiology Unit, Department of Clinical Sciences, Lund University, Clinical Research Center Building 91, Level 10, Jan Waldenströms gata 35, SE-205 02 Malmö, Sweden e-mail: frida.renstrom@med.lu.se

F. Renström • F. B. Hu $\cdot$ P. W. Franks

Department of Nutrition, Harvard T.H. Chan School of Public

Health, Boston, MA, USA

F. Renström

Department of Biobank Research, Umeå University, Umeå, Sweden

\section{G. Hallmans}

Section for Nutritional Research, Department of Public Health and Clinical Medicine, Umeå University, Umeå, Sweden

H. Mulder

Unit of Molecular Metabolism, Department of Clinical Sciences,

Lund University, Malmö, Sweden

J. C. Florez

Center for Human Genetic Research and Diabetes Research Center (Diabetes Unit), Massachusetts General Hospital, Boston, MA, USA

\section{J. C. Florez}

Program in Medical and Population Genetics, Broad Institute, Cambridge, MA, USA

\section{J. C. Florez}

Department of Medicine, Harvard Medical School,

Boston, MA, USA

P. W. Franks

Section for Medicine, Department of Public Health and Clinical Medicine, Umeå University, Umeå, Sweden energy metabolism. Here we tested whether season modified the relationship of these loci with blood glucose concentration.

Methods SNPs rs8192440 (CRY1), rs11605924 (CRY2) and rs10830963 (MTNR1B) were genotyped in a prospective cohort study from northern Sweden $(n=16,499)$. The number of hours of daylight exposure during the year ranged from 4.5 to $22 \mathrm{~h}$ daily. Owing to the non-linear distribution of daylight throughout the year, season was dichotomised based on the vernal and autumnal equinoxes. Effect modification was assessed using linear regression models fitted with a SNP $\times$ season interaction term, marginal effect terms and putative confounding variables, with fasting or $2 \mathrm{~h}$ glucose concentrations as outcomes.

Results The rs8192440 (CRY1) variant was only associated with fasting glucose among participants $(n=2,318)$ examined during the light season ( $\beta=-0.04 \mathrm{mmol} / \mathrm{l}$ per A allele, $95 \% \mathrm{CI}$ $\left.-0.08,-0.01, p=0.02, p_{\text {interaction }}=0.01\right)$. In addition to the established association with fasting glucose, the rs11605924 (CRY2) and rs10830963 (MTNR1B) loci were associated with $2 \mathrm{~h}$ glucose concentrations ( $\beta=0.07 \mathrm{mmol} / \mathrm{l}$ per A allele, $95 \%$ CI $0.03,0.12, p=0.0008, n=9,605$, and $\beta=-0.11 \mathrm{mmol} / 1 \mathrm{per}$ $\mathrm{G}$ allele, 95\% CI $-0.15,-0.06, p<0.0001, n=9,517$, respectively), but only in participants examined during the dark season ( $p_{\text {interaction }}=0.006$ and 0.04 , respectively). Repeated measures analyses including data collected 10 years after baseline $(n=3,500)$ confirmed the results for the $C R Y 1$ locus ( $\left.p_{\text {interaction }}=0.01\right)$.

Conclusions/interpretation In summary, these observations suggest a biologically plausible season-dependent association between SNPs at CRY1, CRY2 and MTNRIB and glucose homeostasis.

Keywords Circadian rhythm - CRY1 - CRY2 - GLACIER Study · Glucose homeostasis $\cdot$ MTNR1B . Season 


$\begin{array}{ll}\text { Abbreviations } \\ \text { BMAL1 } & \text { Brain and muscle ARNT-like 1 } \\ \text { CLOCK } & \text { Circadian locomotor output cycles kaput } \\ \text { CRY } & \text { Cryptochrome } \\ \text { GLACIER } & \begin{array}{l}\text { Gene-Lifestyle interactions And Complex traits } \\ \text { Involved in Elevated disease Risk }\end{array} \\ \text { GRS } & \text { Genetic risk score } \\ \text { MT2 } & \text { Melatonin receptor protein 2 } \\ \text { MTNR1B } & \text { Melatonin receptor 1B } \\ \text { SNP } & \text { Single nucleotide polymorphism }\end{array}$

\section{Introduction}

Genetic variation and circadian rhythmicity influence glucose homeostasis [1,2], but interactions between these factors have received little attention. Circadian rhythmicity functions through an autoregulated negative feedback loop with an oscillating activation and repression of genes with daily, seasonal and annual rhythms. The activating arm is driven by two transcription factors: circadian locomotor output cycles kaput (CLOCK) and brain and muscle ARNT-like 1 (BMAL1). When activated, CLOCK and BMAL1 enhance the expression of the key transcription factors of the inhibitory armperiod 1-3 (PER1-3) and cryptochrome (CRY) 1 and 2which in turn inhibit the activity of CLOCK and BMAL1 [2]. The function of most human tissues is believed to be under the influence of their own rhythmicity or 'intrinsic clock'. Through neural (autonomic nervous system) and endocrine (e.g. melatonin) signalling, the master clock in the brain's suprachiasmatic nucleus synchronises the tissuespecific intrinsic clocks to the photoperiod (the time between sunrise and sunset) in response to signals from retinal photoreceptors communicating the presence of daylight. External environmental timing signals (e.g. sleep and feeding patterns, and daylight) cue the regulation of the internal clocks, which influence physiological processes and energy homeostasis to maximise adaptation and fitness [2]. Studies of perturbations of the circadian clock in humans (e.g. via sleep deprivation or shift work) have established links with metabolic dyshomeostasis (e.g. hyperglycaemia, hyperinsulinaemia and decreased leptin levels) [3, 4] and type 2 diabetes [5].

Elsewhere, variants in genes regulating the circadian clock have been shown to be associated with energy homeostasis. Genetic variation at $C R Y 2$ (rs11605924) and MTNR1B (rs10830963) were among the top hits in a genome-wide association study for fasting glucose concentrations conducted by the Meta-Analyses of Glucose and Insulin-related traits Consortium (MAGIC) [1]. The MTNR1B variant is an established locus associated with type 2 diabetes, and variants at $C R Y 2$ have been tentatively associated with type 2 diabetes [6]. In human islets, the expression of CRY2 mRNA has been shown to be negatively correlated with levels of glycated haemoglobin, and the expression of CRY2 mRNA was lower in participants with type 2 diabetes [7]. Several recently published studies have further indicated the importance of $C R Y 2$ and its circadian co-regulator $C R Y 1$ on glucose metabolism and energy homeostasis in mice [8-10].

CRY1, CRY2 and melatonin receptor 1B (MTNR1B) have established roles in regulating the circadian rhythm, which in turn affects glucose homeostasis. The single nucleotide polymorphisms (SNPs) we selected at the CRY2 and MTNR1B loci are those that have previously been robustly shown to be associated with blood glucose concentrations [1]. Here we tested whether common genetic variation at $C R Y 1, C R Y 2$ and $M T N R 1 B$ associates with fasting and post-challenge glucose concentrations in a season-dependent manner in a population of 16,499 adults from northern Sweden, a region with an extensive annual variation in daylight (annual range $4.5-22 \mathrm{~h}$ day).

\section{Methods}

The Gene-Lifestyle interactions And Complex traits Involved in Elevated disease Risk (GLACIER) Study [11, 12], is a population-based prospective cohort study of $\sim 19,000$ adults of European ancestry, nested within the Northern Sweden Health and Disease Study at the Department of Biobank Research, Umeå University [13]. Clinical characteristics and extensive information on lifestyle behaviours were obtained within the framework of the Västerbotten Health Survey (also known as the Västerbotten Intervention Program), a population-wide health screening initiative that began in 1985. In the year of their 40th, 50th and 60th birthdays, all residents within the county of Västerbotten (current population 260,000 ) are invited to their primary healthcare centre to attend a comprehensive clinical health examination. Within the GLACIER cohort, baseline examinations were conducted between 1990 and 2009, with 5,000 participants currently having data from a 10-year follow-up visit. Participants with self-reported diabetes and/or glucose concentrations indicative of type 2 diabetes [14] were excluded. In total, up to 16,499 participants were eligible for the current analyses, of whom up to 4,751 had data available from a 10-year follow-up examination. Written informed consent was obtained from all the participants, and the Regional Ethical Review Board in Umeå approved all aspects of the study.

\section{Clinical measurements}

Clinical examinations were conducted throughout the year, as previously described $[12,13]$. The participants arrived at the healthcare centre in the morning following an overnight fast. Fasting capillary blood was collected, and additional capillary blood samples were subsequently drawn at a time point $2 \mathrm{~h}$ 
into a 75 g OGTT. Plasma glucose was assessed using a Reflotron bench-top analyser (Roche Diagnostics Scandinavia, Bromma, Sweden) [13]. For the initial blood draw, $83 \%$ of participants reported having fasted for at least $8 \mathrm{~h}, \sim 3 \%$ for between 4 and $8 \mathrm{~h}$ and $\sim 1 \%$ for less than $4 \mathrm{~h}$, and information on fasting status was unavailable for $13 \%$. In sensitivity analysis, fasting status did not materially alter the results. All analyses were, however, adjusted for fasted status.

Environmental exposure assessments and classification

The GLACIER Study is set within the county of Västerbotten, approximately $400 \mathrm{~km}$ (250 miles) south of the Arctic Circle in northern Sweden. The number of hours of daylight at the summer and winter solstices are $\sim 22$ and $\sim 4.5 \mathrm{~h}$, respectively [15]. At this latitude, the change in daylight exposure is nonlinear. To test the hypothesis that seasonal differences related to daylight exposure modify the association of circadianrelated loci with glucose homeostasis, the year was divided into a light (1 May-31 October) and a dark (1 November-30 April) season, each of 6 months' duration, setting the cut-offs approximately 6 weeks after the vernal and autumnal equinoxes (late March and late September, respectively). In association with the health examination, the participants also complete a self-administered lifestyle questionnaire, covering socioeconomic factors, psychosocial health, and diet and physical activity; the latter were assessed using a validated, selfadministered Food Frequency Questionnaire [16] and a modified version of the International Physical Activity Questionnaire [17], respectively.

\section{Genotyping}

Genomic DNA was extracted from participants' peripheral white blood cells and diluted to $4 \mathrm{ng} / \mu \mathrm{l}$. Genotyping of rs11605924 (CRY2) and rs10830963 (MTNR1B) was performed using the Sequenom iPLEX platform (Sequenom, San Diego, CA, USA). Genotype concordance (tested with duplicates on one in ten samples) was $>99 \%$ [11]. The rs8192440 (CRY1) variant was extracted from the MetaboChip array (Illumina, San Diego, CA, USA) [18], which was available for a subset of the total number of GLACIER participants $(n=5,806)$. The success rate for genotyping was $>96 \%$, and all three SNPs were in HardyWeinberg equilibrium $(p>0.05)$.

Statistical analysis

All analyses were run in SAS v9.3 (SAS Institute, Cary, NC, USA). Generalised linear models were used for crosssectional analyses, and linear mixed models were used to model repeated-measures data, fitted with a random slope, a random intercept and a continuous indicator variable quantifying the time (in years) between the follow-up and baseline visits, using compound symmetry for the variancecovariance structure.

All models were adjusted for age, sex, fasting status and BMI. Interaction models also included a product term $(\mathrm{SNP} \times$ season) and marginal effect terms (SNP and season). Because $2 \mathrm{~h}$ glucose concentrations are influenced by fasting glucose levels [11], the models were further adjusted for fasting glucose when $2 \mathrm{~h}$ glucose was the outcome measure. To investigate aggregated effects of the MTNR1B and CRY2 loci on $2 \mathrm{~h}$ glucose levels, a genetic risk score (GRS) was constructed by summing the (trait-elevating) effect alleles for each participant, as previously described [11]. To control for confounding, additional models were run adjusting for smoking (yes/no), level of education (compulsory school/ college/university) and intake of total energy $(\mathrm{kJ} /$ day), fruit (g/day), vegetables (g/day) and whole grains (g/day). Leisure time physical activity level, categorised as active ( $\geq 1$ time/week) and inactive ( $<1$ time/week), increases in the long summer vacation period in Sweden and may confound or mediate the association of season and glucose concentrations; thus, physical activity was added in a separate step (included in the fully adjusted model unless otherwise indicated).

\section{Results}

The characteristics of the participants at baseline are shown in Table 1.

Compared with the light season (May-October), the baseline fasting glucose concentrations were on average $0.03 \mathrm{mmol} / 1$ higher $(p=0.001,95 \%$ CI $0.05,0.01, n=16$, 499) in participants examined during the dark season (November-April). No significant association between season and $2 \mathrm{~h}$ glucose levels was observed before $(\beta=0.03 \mathrm{mmol} / \mathrm{l}$, $95 \% \mathrm{CI}-0.03,0.08, p=0.33, n=15,917$ ) or after adjustment for fasting glucose $(\beta=0.04 \mathrm{mmol} / 1,95 \% \mathrm{CI}-0.004,0.09$, $p=0.07, n=15,917)$. No association was observed between season and BMI at baseline $(\beta=-0.09 \mathrm{mmol} / 1,95 \% \mathrm{CI}$ $-0.21,0.04, p=0.17, n=16,499)$.

Associations and interactions at baseline

rs8192440 (CRY1) and baseline blood glucose concentrations No association was observed between the rs8192440 (CRY1) variant and fasting or $2 \mathrm{~h}$ glucose $(\beta=$ $-0.008 \mathrm{mmol} / 1$ per A allele, $95 \%$ CI $-0.04,0.02, p=0.51$, $n=5,806$ and $\beta=0.02 \mathrm{mmol} / 1$ per A allele, $95 \% \mathrm{CI}-0.03$, $0.07, p=0.69, n=5,663$, respectively). However, there was a statistically significant interaction between SNP and season $\left(p_{\text {interaction }}=0.01\right)$; when the data were stratified by season, the A allele was associated with lower fasting glucose 
Table 1 Characteristics of the GLACIER Study participants at baseline, Sweden, 1990-2009

\begin{tabular}{|c|c|c|c|c|c|c|c|}
\hline \multirow[b]{3}{*}{ Variable } & \multicolumn{2}{|l|}{ All } & \multicolumn{2}{|l|}{ Light season $^{\mathrm{a}}$} & \multicolumn{2}{|l|}{ Dark season $^{\mathrm{b}}$} & \multirow[t]{3}{*}{$p$ for trend ${ }^{\mathrm{c}}$} \\
\hline & \multicolumn{2}{|l|}{$(n=16,499)$} & \multicolumn{2}{|l|}{$(n=6,489)$} & \multicolumn{2}{|l|}{$(n=10,010)$} & \\
\hline & Mean or $n$ & $\mathrm{SD}$ or $\%$ & Mean or $n$ & $\mathrm{SD}$ or $\%$ & Mean or $n$ & $\mathrm{SD}$ or $\%$ & \\
\hline Sex (male/female) & $6,600 / 9,899$ & $40 / 60$ & $2,509 / 3,980$ & $39 / 61$ & $4,091 / 5,919$ & $41 / 59$ & 0.005 \\
\hline Age (years) & 52.3 & 8.8 & 52.1 & 8.8 & 52.4 & 8.7 & 0.02 \\
\hline BMI $\left(\mathrm{kg} / \mathrm{m}^{2}\right)$ & 25.9 & 4.1 & 25.8 & 4.0 & 26.0 & 4.1 & 0.07 \\
\hline Fasting glucose (mmol/l) & 5.37 & 0.63 & 5.35 & 0.64 & 5.39 & 0.63 & 0.0001 \\
\hline $2 \mathrm{~h}$ glucose $(\mathrm{mmol} / \mathrm{l})^{\mathrm{d}}$ & 6.80 & 1.66 & 6.82 & 1.64 & 6.80 & 1.67 & 0.41 \\
\hline TEI (kJ/day) & 7,263 & 2,616 & 7,212 & 2,604 & 7,292 & 2,625 & 0.06 \\
\hline Alcohol intake (g/day) & 3.5 & 4.6 & 3.5 & 4.9 & 3.5 & 4.4 & 0.87 \\
\hline PA (active/inactive) ${ }^{\mathrm{e}}$ & $4,109 / 11,439$ & $26 / 74$ & $1,568 / 4,505$ & $26 / 74$ & $2,541 / 6,934$ & $27 / 73$ & 0.17 \\
\hline Smoking (never/ex/current) & $9,026 / 3,657 / 3,565$ & $56 / 22 / 22$ & $3,534 / 1,415 / 1,419$ & $56 / 22 / 22$ & $5,492 / 2,242 / 2,146$ & $55 / 23 / 22$ & 0.62 \\
\hline Educational level $^{\mathrm{f}}$ & $6,379 / 6,726 / 3,244$ & $39 / 41 / 20$ & $2,520 / 2,644 / 1,258$ & $39 / 41 / 20$ & $3,859 / 4,082 / 1,986$ & $39 / 41 / 20$ & 0.79 \\
\hline
\end{tabular}

${ }^{\mathrm{a}} 1$ May-31 October

b 1 November-30 April

${ }^{\mathrm{c}}$ ANOVA for continuous characteristics and $\chi^{2}$ test for categorical characteristics

d Available for 15,917 participants

${ }^{\mathrm{e}}$ Active, $\geq 1$ time/week; inactive, $<1$ time/week

${ }^{\mathrm{f}}$ Categorised into three levels: compulsory school, college and university

PA, leisure time physical activity; TEI, total energy intake

concentrations ( $\beta=-0.04 \mathrm{mmol} / \mathrm{l}$ per A allele, $95 \% \mathrm{CI}-0.08$, $-0.01, p=0.02$ ) among participants who were assessed during the light season $(n=2,318)$, whereas no association was observed in those $(n=3,488)$ assessed during the dark season ( $\beta=0.01 \mathrm{mmol} / \mathrm{l}$ per A allele, $95 \% \mathrm{CI}-0.02,0.04, p=0.33$ ) (Fig. 1a). Adjusting for lifestyle factors reduced the statistical significance of the interaction effect $\left(p_{\text {interaction }}=0.03\right)$, which was further mitigated by additionally adjusting for physical activity $\left(p_{\text {interaction }}=0.06\right)$.

rs11605924 (CRY2) and baseline glucose concentrations As previously reported [11], the A allele at rs11605924 (CRY2) was associated with fasting $(\beta=0.03 \mathrm{mmol} / \mathrm{l}$ per A allele, $95 \%$ CI $0.02,0.05, p<0.0001, n=16,397)$ and $2 \mathrm{~h}(\beta=0.04 \mathrm{mmol} / 1$ per A allele, $95 \%$ CI $0.002,0.07, p=0.04, n=15,820$ ) glucose concentrations in the GLACIER cohort. As shown in Fig. 2a, the association between the $C R Y 2$ variant and the $2 \mathrm{~h}$ glucose concentration depended on the season ( $\left.p_{\text {interaction }}=0.006\right)$; the A allele was associated with higher $2 \mathrm{~h}$ glucose concentrations among participants undergoing the OGTT during the dark season $(\beta=0.07 \mathrm{mmol} / \mathrm{l}$ per A allele, $95 \%$ CI $0.03,0.12, p=$ $0.0008, n=9,605)$, whereas no association was observed among participants $(n=6,215)$ examined during the light season $(\beta=-0.02 \mathrm{mmol} / \mathrm{l}$ per A allele, $95 \% \mathrm{CI}-0.08,0.03, p=$ $0.39)$. Adjusting for lifestyle factors had no material effect on the results, whereas additionally adjusting for physical activity slightly increased the statistical significance of the interaction effect ( $\left.p_{\text {interaction }}=0.005\right)$. No interaction between season and CRY2 was observed for fasting glucose levels (data not shown).

rs10830963 (MTNR1B) and baseline glucose concentrations In addition to the association between the rs10830963 $(M T N R 1 B)$ variant and fasting glucose concentrations $(\beta=$ $0.09 \mathrm{mmol} / \mathrm{l}$ per $\mathrm{G}$ allele, $95 \% \mathrm{CI} 0.07,0.10, p<0.0001, n=$ $16,268)$, the $\mathrm{G}$ allele was associated with lower $2 \mathrm{~h}$ glucose in the GLACIER cohort ( $\beta=-0.07 \mathrm{mmol} / \mathrm{l}$ per $\mathrm{G}$ allele, $95 \% \mathrm{CI}$ $-0.11,-0.03, p=0.0002, n=15,691)$, as previously reported [11]. In analyses stratified by season (Fig. 3a), the $G$ allele was associated with lower $2 \mathrm{~h}$ glucose among participants $(n=9$, 517 ) studied in the dark season ( $\beta=-0.11 \mathrm{mmol} / \mathrm{l}$ per $\mathrm{G}$ allele, $95 \% \mathrm{CI}-0.15,-0.06, p<0.0001)$, but not among participants $(n=6,174)$ examined during the light season $(\beta=-0.02 \mathrm{mmol} /$ 1 per $\mathrm{G}$ allele, $\left.95 \% \mathrm{CI}-0.08,0.04, p=0.46 ; p_{\text {interaction }}=0.04\right)$. Adjusting for lifestyle factors slightly strengthened the significance of the interaction effect $\left(p_{\text {interaction }}=0.03\right)$, which was further strengthened by adjusting for physical activity $\left(p_{\text {interaction }}=0.01\right)$. No interaction of season and MTNR $1 B$ variation on fasting glucose concentrations was observed (data not shown).

Combined effects of CRY2 and MTNR1B on $2 \mathrm{~h}$ glucose concentrations Each unit increase (one additional effect allele) of the GRS was associated with $0.05 \mathrm{mmol} / \mathrm{l}$ higher $2 \mathrm{~h}$ 

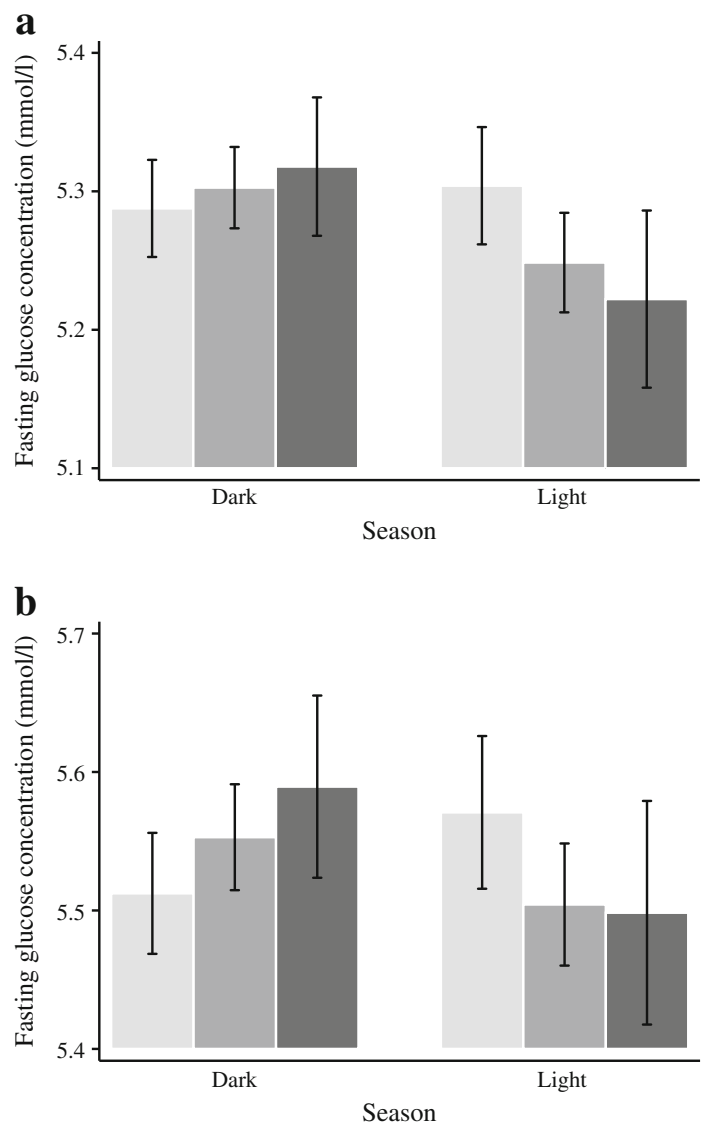

Fig. 1 The association between rs8192440 (CRY1) and fasting glucose concentrations stratified by season in the GLACIER cohort. (a) Analysis conducted at baseline $\left(n=5,806 ; p_{\text {interaction }}=0.01\right)$. Number of participants in each genotype group (dark/light season): GG $(n=1,195 / 820)$, GA $(n=$ $1,704 / 1,139)$ and AA $(n=589 / 359)$. (b) Analysis conducted in the reduced sample of participants $(n=3,500)$ with data available from a reexamination at an average of 10 years later $\left(p_{\text {interaction }}=0.008\right)$. Number of participants in each genotype group (dark/light season): GG $(n=753$ / 473), GA $(n=982 / 739)$ and AA $(n=332 / 221)$. Linear regression model adjusted for age, sex, BMI and fasted status. Results are presented as adjusted means by genotype, with $95 \%$ CIs. Light grey bar, GG genotype; medium grey bar, GA genotype; dark grey bar, AA genotype

glucose concentrations ( $95 \%$ CI $0.03,0.08, p<0.0001, n=15$, 594). The observed association was of a greater magnitude in participants $(n=9,461)$ examined during the dark season $(\beta=$ $0.09 \mathrm{mmol} / \mathrm{l}$ per allele, $95 \%$ CI $0.05,0.12, p<0.0001)$, compared with those $(n=6,133)$ assessed during the light season ( $\beta=-0.002 \mathrm{mmol} / 1$ per allele, $95 \% \mathrm{CI}-0.04,0.04, p=0.93$, $p_{\text {interaction }}=0.0009$ ). Adjusting for lifestyle factors slightly strengthened the statistical significance of the interaction ( $\left.p_{\text {interaction }}=0.0008\right)$, which was further strengthened by additionally adjusting for physical activity $\left(p_{\text {interaction }}=0.0002\right)$.

Repeated-measures analyses

Relevant data for follow-up and repeated measures analysis were available for a total of 3,500 (CRY1) and 4,751 (CRY2 and MTNR1B) GLACIER Study participants who attended a
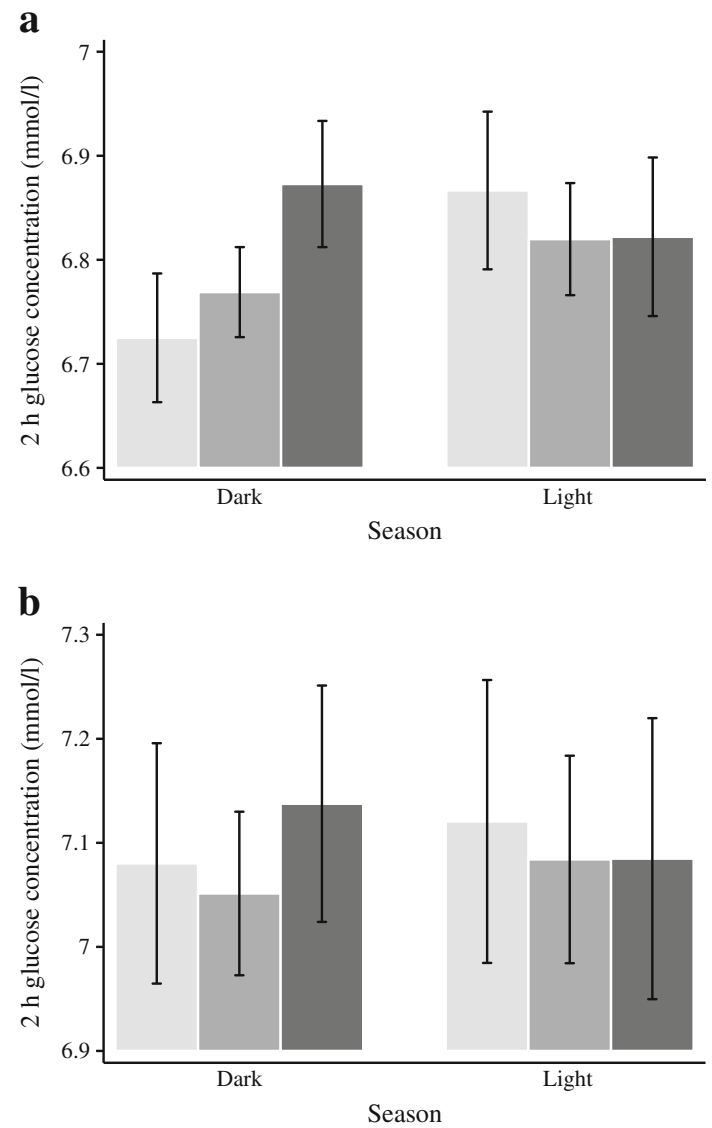

Fig. 2 The association between rs11605924 (CRY2) and $2 \mathrm{~h}$ glucose concentrations following a $75 \mathrm{~g}$ OGTT stratified by season in the GLACIER cohort. (a) Analysis conducted at baseline $\left(n=15,820 ; p_{\text {interaction }}=0.006\right)$. Number of participants in each genotype group (dark/light season): $\mathrm{CC}$ ( $n=$ $2,351 / 1,567), \mathrm{CA}(n=4,807 / 3,100)$ and AA $(n=2,447 / 1,548)$. (b) Analysis conducted on the reduced sample of participants $(n=4,650)$ with data available from a re-examination approximately 10 years later $\left(p_{\text {interaction }}=0.46\right)$. Number of participants in each genotype group (dark/light season): $\mathrm{CC}$ ( $n=$ $665 / 480)$, CA $(n=1,437 / 893)$ and AA $(n=688 / 487)$. Linear regression model adjusted for age, sex, BMI, fasted status and fasting glucose level. Results are presented as adjusted means by genotype, with $95 \%$ CIs. Light grey bar, CC genotype; medium grey bar, CA genotype; dark grey bar, AA genotype

follow-up examination a decade after the baseline visit (mean follow-up time $9.9 \pm 0.5$ years) (Table 2 ).

rs8192440 (CRY1) and 10-year follow-up measures of fasting glucose concentrations Assessed in the reduced sample with 10 -year follow-up data $(n=3,500)$, the interaction between the $C R Y 1 \mathrm{SNP}$ and season was directionally consistent with the baseline observation $\left(p_{\text {interaction }}=0.008\right)$ : the $\mathrm{A}$ allele was associated with lower fasting glucose concentrations $(\beta=$ $-0.04 \mathrm{mmol} / \mathrm{l}$ per A allele, $95 \% \mathrm{CI}-0.09,0.004, p=0.07$ ) among participants who were assessed during the light season $(n=1,433)$, with an opposite direction of association in those $(n=2,067)$ assessed during the dark season $(\beta=0.04 \mathrm{mmol} / \mathrm{l}$ per A allele, 95\% CI 0.0008, 0.08, $p=0.05$ ) (Fig. 1b). Additionally adjusting for lifestyle factors did not materially 

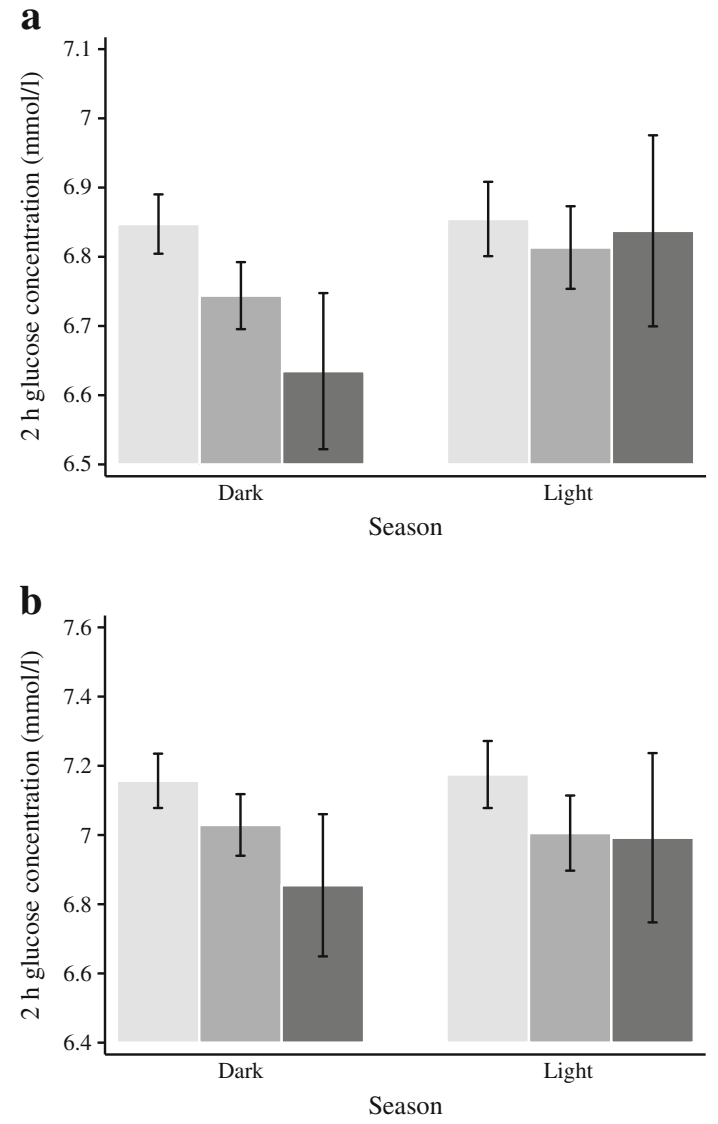

Fig. 3 The association between rs $10830963(M T N R 1 B)$ and $2 \mathrm{~h}$ glucose concentrations following a $75 \mathrm{~g}$ OGTT stratified by season in the GLAC IER cohort. (a) Analysis conducted at baseline $\left(n=15,691 ; p_{\text {interaction }}=\right.$ 0.04). Number of participants in each genotype group (dark/light season): CC $(n=4,934 / 3,151)$, CG $(n=3,869 / 2,547)$ and GG $(n=714 / 476)$. (b) Analysis conducted for the reduced sample of participants $(n=4,610)$ with data available from a re-examination approximately 10 years later $\left(p_{\text {interaction }}=0.83\right)$. Number of participants in each genotype group (dark/light season): CC $(n=1,437 / 945), \mathrm{CG}(n=1,120 / 750)$, and GG $(n=210 / 148)$. Linear regression model adjusted for age, sex, BMI, fasted status and fasting glucose level. Results are presented as adjusted means by genotype, with $95 \%$ CIs. Light grey bar, CC genotype; medium grey bar, CG genotype; dark grey bar, GG genotype

change the magnitude or statistical significance of the interaction effect. Repeated measures analyses combining all the available baseline and follow-up data yielded consistent interaction results ( $p_{\text {interaction }}=0.01, n=3,394, n_{\text {observations }}=6,788$ ), which remained statistically significant after adjusting for physical activity and other lifestyle variables ( $p_{\text {interaction }}=$ $\left.0.02, n=3,364, n_{\text {observations }}=6,255\right)$.

rs11605924 (CRY2) and 10-year follow-up measures of $2 \mathrm{~h}$ glucose concentrations Although the interaction of the CRY2 variant with season was directionally consistent with the baseline result, the results of the analysis using the subset of participants with 10 -year follow-up data $(n=4,650)$ were not statistically significant ( $p_{\text {interaction }}=0.46$ ): the A allele showed a positive direction of association with higher $2 \mathrm{~h}$ glucose concentrations during the dark season $(\beta=0.03 \mathrm{mmol} / \mathrm{l}$ per $\mathrm{G}$ allele, $95 \% \mathrm{CI}-0.05,0.11, p=0.46 n=2,790)$, with an opposite direction of association during the light season $(\beta=$ $-0.02 \mathrm{mmol} / \mathrm{l}$ per A allele, $95 \% \mathrm{CI}-0.12,0.08, p=0.69, n=$ 1,860) (Fig. 2b). Additionally adjusting for lifestyle factors did not materially change the magnitude or statistical significance of the interaction effect. In repeated measures analysis of the baseline and follow-up visits, the interaction of the CRY2 variant with season was directionally consistent with the baseline results, but not statistically significant $\left(p_{\text {interaction }}=0.23, n=4,269, n_{\text {observations }}=8,287\right)$.

rs10830963 (MTNR1B) and 10-year follow-up measures of $2 \mathrm{~h}$ glucose concentrations In the smaller sample of participants with 10-year follow-up data $(n=4,610)$, the interaction seen at baseline between the MTNR1B variant and season was no longer statistically significant ( $p_{\text {interaction }}=0.83$ ): the $\mathrm{G}$ allele was inversely associated with $2 \mathrm{~h}$ glucose concentrations during both seasons (light season: $\beta=-0.13 \mathrm{mmol} / \mathrm{l}$ per $\mathrm{G}$ allele, $95 \% \mathrm{CI}-0.24,-0.02, p=0.02 n=1,843$; and dark season: $\beta=-0.14 \mathrm{mmol} / 1$ per $\mathrm{G}$ allele, $95 \% \mathrm{CI}-0.23,-0.05$, $p=0.003, n=2,767$ ) (Fig. 3b). The interaction between the $M T N R 1 B$ variant and season was not statistically significant in the repeated measures analysis using baseline and followup data ( $\left.p_{\text {interaction }}=0.57, n=4,236, n_{\text {observations }}=8,219\right)$.

\section{Discussion}

Interactions between variants at $C R Y 1, C R Y 2$ and $M T N R 1 B$ and seasonal differences related to daylight exposure in relation to blood glucose homeostasis are biologically plausible and may be of clinical relevance, although no large epidemiological studies have to our knowledge examined this hypothesis. Here we tested these hypotheses in a prospective cohort study set within a region where annual daylight exposure varies extensively (annual range $4.5-22 \mathrm{~h}$ per day). We found a novel association between the $C R Y 1$ variant and fasting glucose concentrations that was only evident in participants studied during the lighter part of the year (May-October). In addition to the established association of the $C R Y 2$ and $M T N R 1 B$ locus with fasting glucose concentration [1, 11], novel associations between the $C R Y 2$ and MTNR1B variants with $2 \mathrm{~h}$ glucose concentrations were observed, but only for the darker season (November-April). Adjustments for lifestyle factors known to vary by season, which might confound or mediate the observed interactions, had little impact on the results. In a reduced study sample, the interaction results for the $C R Y 1$ variant were supported by 10-year follow-up and repeated measures analysis, whereas this was not the case for the $C R Y 2$ and MTNRIB variants.

Ideally, observations of the nature reported here should be replicated and extended into intervention settings before 
Table 2 Characteristics of the 4,751 GLACIER participants with available follow-up data, Sweden, 1992-2008

\begin{tabular}{|c|c|c|c|c|c|c|c|}
\hline \multirow[b]{3}{*}{ Variable } & \multicolumn{2}{|l|}{ All } & \multicolumn{2}{|l|}{ Light season $^{\mathrm{a}}$} & \multicolumn{2}{|l|}{ Dark season $^{\mathrm{b}}$} & \multirow[t]{3}{*}{$p$ for trend } \\
\hline & \multicolumn{2}{|l|}{$(n=4,751)$} & \multicolumn{2}{|l|}{$(n=1,899)$} & \multicolumn{2}{|l|}{$(n=2,852)$} & \\
\hline & Mean or $n$ & $\mathrm{SD}$ or $\%$ & Mean or $n$ & $\mathrm{SD}$ or $\%$ & Mean or $n$ & $\mathrm{SD}$ or $\%$ & \\
\hline Sex (male/female) & $1,713 / 3,028$ & $36 / 64$ & $691 / 1,208$ & $36 / 64$ & $1,022 / 1,830$ & $36 / 64$ & 0.70 \\
\hline Age (years) & 55.2 & 6.6 & 55.3 & 6.5 & 55.2 & 6.7 & 0.54 \\
\hline BMI $\left(\mathrm{kg} / \mathrm{m}^{2}\right)$ & 26.2 & 4.0 & 26.1 & 4.1 & 26.3 & 4.0 & 0.40 \\
\hline Fasting glucose (mmol/l) & 5.54 & 0.62 & 5.52 & 0.63 & 5.56 & 0.62 & 0.05 \\
\hline $2 \mathrm{~h}$ glucose $(\mathrm{mmol} /)^{\mathrm{d}}$ & 7.08 & 1.63 & 7.07 & 1.64 & 7.09 & 1.62 & 0.72 \\
\hline TEI (kJ/day) & 6,698 & 2,323 & 6,806 & 2,390 & 6,626 & 2,277 & 0.01 \\
\hline Alcohol intake (g/day) & 4.0 & 4.7 & 4.1 & 4.7 & 4.0 & 4.7 & 0.80 \\
\hline PA (active/inactive) ${ }^{\mathrm{e}}$ & $1,616 / 3,039$ & $35 / 65$ & $626 / 1,230$ & $34 / 66$ & $990 / 1,809$ & $35 / 65$ & 0.25 \\
\hline Smoking (never/ex/current) & $2,718 / 1,212 / 776$ & $58 / 26 / 16$ & $1,069 / 498 / 312$ & $57 / 26 / 17$ & $1,649 / 714 / 465$ & $58 / 25 / 17$ & 0.57 \\
\hline Educational level ${ }^{\mathrm{f}}$ & $1,355 / 2,160 / 1,211$ & $29 / 46 / 25$ & $570 / 845 / 469$ & $30 / 45 / 25$ & $785 / 1,315 / 742$ & $28 / 46 / 26$ & 0.14 \\
\hline
\end{tabular}

Mean follow-up time was $9.9 \pm 0.5$ years (range $1-13$ years)

${ }^{\text {a }} 1$ May-31 October

b 1 November-30 April

${ }^{\mathrm{c}}$ ANOVA for continuous characteristics and $\chi^{2}$ test for categorical characteristics

d Available for 4,672 participants

e Active, $\geq 1$ time/week; inactive, $<1$ time/week

${ }^{\mathrm{f}}$ Categorised into three levels: compulsory school, college and university

PA, leisure time physical activity; TEI, total energy intake.

conclusions about cause and effect can be drawn. Replication cohorts should ideally be larger than the discovery cohort (i.e. $n>16,000$ ) to avoid 'winner's curse' and other sources of bias germane to interaction replication studies. An appropriate replication cohort would be one where the index $C R Y 1 / 2$ and $M T N R 1 B$ variants, fasting and $2 \mathrm{~h}$ blood glucose, and lifestyle have been measured, and which includes exposure to a wide variation in annual daylight exposure; such cohorts should thus be located at or above the latitude of the GLACIER Study. To our knowledge, no such cohorts exist. For this reason, we undertook internal replication analyses using the 10 year follow-up data from the GLACIER Study. Although we recognise that this does not represent an independent replication of our baseline findings and has other limitations (e.g. that it is likely to be underpowered owing to the smaller sample size), the data provide further support for some of our initial findings. In addition, no statistically significant interactions (Bonferroni corrected $p<0.05 / 28$ ) were identified in secondary analysis intended to control for the possibility that the interactions we reported were observed for SNPs in or near genes previously associated with fasting glucose concentrations that are not known to modulate circadian rhythm (data not shown) [1]. Nevertheless, our results should be viewed as generating a hypothesis that requires further investigation by others.

Epidemiological studies, while useful for generating hypotheses, are poorly suited to inferring causal effects owing to the potential for confounding and reverse causation. Although we controlled for putative confounding factors (with no material influence on the results overall), this does not exclude the possibility that our findings are confounded by unmeasured factors that vary by season, such as physical activity, temperature and mood. Another limitation is that the lifestyle questionnaires used here focused on behaviours in the previous year, and recent behaviours may be more relevant in the context of the current analyses.

The notion that alterations in the transcriptional and translational feedback loop that cues circadian rhythmicity influence energy homeostasis is supported by the genetic manipulation of key clock regulators in different mice models. CRY1, a key regulator of the inhibitory arm of circadian rhythmicity, has been implicated as a key modulator of the intrinsic liver clock: the Cryl gene is rhythmically expressed, with higher protein levels seen during the transition from night to day, where CRY1 reduces hepatic gluconeogenesis [8]. Mice deficient in CRY1 that are kept on a high-fat diet gain less weight than their wild-type littermates despite comparable levels of energy intake, whereas mice deficient in both CRY1 and CRY2 are susceptible to obesity despite lower energy intake, and show enhanced insulin secretion [9,10]. When fed normal chow, mice deficient in CRY1 or CRY2 do not differ phenotypically from wild-type mice [10], whereas mice deficient in both CRY1 and CRY2 gain less fat mass and increase their 
basal metabolic rate. These animals also display impaired glucose metabolism with a higher and delayed peak in blood glucose levels following an OGTT [19]. Knocking out Cryl shortens the animals' intrinsic circadian rhythm by $\sim 1 \mathrm{~h}$ compared with wild-type mice, whereas knocking out Cry2 prolongs this period by $\sim 1 \mathrm{~h}$. Simultaneously knocking out both Cry genes renders the animals' sleep/wake patterns arrhythmic but only when the animals are exposed to constant darkness; they maintain normal rhythmicity under normal light/dark cycles $[20,21]$.

In humans, it is thus possible that the master clock in the suprachiasmatic nucleus is able to maintain a normal circadian rhythmicity during normal daylight exposure (approximating a $12 \mathrm{~h} \mathrm{light} / 12 \mathrm{~h}$ dark cycle). However, under conditions where the circadian system is perturbated by extreme levels of daylight exposure (e.g. at geographical locations where daylight is almost constant or completely absent during the summer and winter periods, respectively), alterations in the activity of the CRY proteins might occur, leading to behavioural and molecular circadian arrhythmicity that influence glucose homeostasis.

MTNR1B encodes one of the two melatonin receptor proteins (MT2). Melatonin is a hormone secreted primarily from the pineal gland [22]. A primary role of melatonin is to signal to the rest of the body that night has begun, with levels 10 -fold higher at night than during the day. The MT2 receptor (which corresponds to MTNR1B in humans) is found in pancreatic beta cells in humans and mice [23, 24]. Binding of melatonin to the MT2 receptor acutely inhibits insulin secretion and may thus participate in regulating the diurnal insulin secretion pattern [2]. MTNRIB is also expressed in all the major tissues involved in glucose homeostasis, such as skeletal muscle, liver, adipose tissue and hypothalamus [25].

The rs 10830963 variant is located within the single intron of MTNR1B. This variant has no apparent effect on transcription factor binding or splicing [26], but has been associated with an overexpression of MTNR1B [23]. An increased sensitivity to the inhibitory effect of melatonin on insulin secretion owing to increased MTNR1B receptor availability is consistent with the higher fasting glucose levels that are seen in carriers of the MTNR1B variant rs10830963 [23], with a modestly increased risk of type 2 diabetes [26, 27]. Despite the decreased insulin response observed during OGTT in MTNR1B carriers, a recent study in humans indicates that the allele of rs10830963, which is associated with fasting glucose levels, might enhance the effect of glucagon-like peptide-1 (incretin) on the insulin response following an oral glucose challenge [28]. Prolonged exposure to melatonin has been shown to potentiate the glucagon-like peptide-1 response through 'melatonin-induced sensitisation' [29], which could explain our observed association with lower $2 \mathrm{~h}$ glucose levels during the dark season. However, defective MTNR1B receptor function as a result of very rare partial or total loss-of-function variants has been linked to a substantially increased risk of type 2 diabetes [30]. Collectively, these results indicate a complex network of tissue-specific effects on glucose homeostasis with melatonin signalling at its centre. The fact that the novel association in this study between the MTNRIB variant and $2 \mathrm{~h}$ glucose levels was only evident during the dark season may be because of the reduced periodic melatonin exposure that occurs during the light season, with a shorter nocturnal melatonin peak caused by the known inhibitory effects of light from an early sunrise on melatonin secretion [31]. Dedicated interventional studies in which humans are given melatonin pulses under controlled lighting conditions might help to clarify the respective influence of genetic and environmental variation on this system.

The observed association of the $C R Y 1$ variant, and the tentative associations of the $C R Y 2$ and MTNR1B variants, with blood glucose concentrations in a season-dependent manner is consistent with established mechanisms through which these genes affect glucose homeostasis. If substantiated, these epidemiological findings further highlight the role of neuroendocrine factors in glucose homeostasis. The results also highlight that the time of day and season of the year in which glucose concentrations are measured may affect the ability to detect genetic associations, because strong environmental factors might sometimes mask genetic influences on metabolic traits.

Acknowledgements The authors thank the participants in the GLACIER Study, and the staff from the Umea Medical Biobank for preparing the materials, and from the Västerbotten Intervention Programme for data collection. The authors also thank K. Enqvist and T. Johansson (Västerbotten's County Council, Umeå, Sweden) for DNA preparation, P. Soule, H. K. Ranu and D. J. Hunter (Harvard T.H. Chan School of Public Health, Boston, MA, USA) and F. Payne and I. Barroso (Wellcome Trust Sanger Institute, Hinxton, UK) for support with genotyping.

Funding The GLACIER Study was funded by project grants from the Swedish Heart-Lung Foundation, the Swedish Diabetes Association, the Påhlsson's Foundation, the Swedish Research Council, the Umea Medical Research Foundation, Novo Nordisk and The Heart Foundation of Northern Sweden (all to PWF). RWK was funded by a grant from the Innovative Medicines Initiative Joint Undertaking under grant agreement no. 115317 (DIRECT) as part of the European Union's Seventh Framework Program (FP7/2007-2013) (to PWF) and a STAR Novo Nordisk co-financed $\mathrm{PhD}$ fellowship. FR was supported by a postdoctoral stipend from the Swedish Heart-Lung Foundation.

Duality of interest The authors declare that there is no duality of interest associated with this manuscript.

Contribution statement PWF designed and obtained funding for the GLACIER Study; FR, RWK, TVV, JCF, HM and PWF contributed to the analytical plan and co-wrote the manuscript; GH and FBH substantially contributed to data acquisition; TVV and FR organised the data; and FR conducted the statistical analyses and wrote the manuscript. All the authors critically appraised the manuscript, contributed to draft revisions and approved the final version to be published. PWF and FR are the guarantors of this work. 


\section{References}

1. Dupuis J, Langenberg C, Prokopenko I et al (2010) New genetic loci implicated in fasting glucose homeostasis and their impact on type 2 diabetes risk. Nat Genet 42:105-116

2. Green CB, Takahashi JS, Bass J (2008) The meter of metabolism. Cell 134:728-742

3. Scheer FA, Hilton MF, Mantzoros CS, Shea SA (2009) Adverse metabolic and cardiovascular consequences of circadian misalignment. Proc Natl Acad Sci U S A 106:4453-4458

4. Delezie J, Challet E (2011) Interactions between metabolism and circadian clocks: reciprocal disturbances. Ann N Y Acad Sci 1243: $30-46$

5. Karlsson B, Knutsson A, Lindahl B (2001) Is there an association between shift work and having a metabolic syndrome? Results from a population based study of 27,485 people. Occup Environ Med 58: 747-752

6. Scott RA, Lagou V, Welch RP et al (2012) Large-scale association analyses identify new loci influencing glycemic traits and provide insight into the underlying biological pathways. Nat Genet 44:9911005

7. Stamenkovic JA, Olsson AH, Nagorny CL et al (2012) Regulation of core clock genes in human islets. Metab Clin Exp 61:978-985

8. Zhang EE, Liu Y, Dentin R et al (2010) Cryptochrome mediates circadian regulation of cAMP signaling and hepatic gluconeogenesis. Nat Med 16:1152-1156

9. Barclay JL, Shostak A, Leliavski A et al (2013) High-fat diet-induced hyperinsulinemia and tissue-specific insulin resistance in Crydeficient mice. Am J Physiol Endocrinol Metab 304:E1053-E1063

10. Griebel G, Ravinet-Trillou C, Beeske S, Avenet P, Pichat P (2014) Mice deficient in cryptochrome 1 (cryl (-/-)) exhibit resistance to obesity induced by a high-fat diet. Front Endocrinol 5:49

11. Renström F, Shungin D, Johansson I et al (2011) Genetic predisposition to long-term nondiabetic deteriorations in glucose homeostasis: ten-year follow-up of the GLACIER study. Diabetes 60:345-354

12. Kurbasic A, Poveda A, Chen Y et al (2014) Gene-lifestyle interactions in complex diseases: design and description of the GLACIER and VIKING studies. Curr Nutr Rep 3:400-411

13. Hallmans G, Ågren A, Johansson G et al (2003) Cardiovascular disease and diabetes in the Northern Sweden Health and Disease Study Cohort - evaluation of risk factors and their interactions. Scand J Public Health Suppl 61:18-24

14. World Health Organization (1999) Definitions, diagnosis and classification of diabetes mellitus and its complications. Part 1: diagnosis and classification of diabetes mellitus. World Health Organization, Geneva

15. www.stjarnhimlen.se/2012/umea.html via the Swedish Meteorological and Hydrological Institute (SMHI). Accessed November 2012
16. Johansson I, Hallmans G, Wikman A, Biessy C, Riboli E, Kaaks R (2002) Validation and calibration of food-frequency questionnaire measurements in the Northern Sweden Health and Disease cohort. Public Health Nutr 5:487-496

17. InterAct C (2012) Validity of a short questionnaire to assess physical activity in 10 European countries. Eur J Epidemiol 27:15-25

18. Voight BF, Kang HM, Ding J et al (2012) The MetaboChip, a custom genotyping array for genetic studies of metabolic, cardiovascular, and anthropometric traits. PLoS Genet 8:e1002793

19. Ikeda H, Yong Q, Kurose T et al (2007) Clock gene defect disrupts light-dependency of autonomic nerve activity. Biochem Biophys Res Commun 364:457-463

20. Thresher RJ, Vitaterna MH, Miyamoto Y et al (1998) Role of mouse cryptochrome blue-light photoreceptor in circadian photoresponses. Science 282:1490-1494

21. Vitaterna MH, Selby CP, Todo T et al (1999) Differential regulation of mammalian period genes and circadian rhythmicity by cryptochromes 1 and 2. Proc Natl Acad Sci U S A 96:12114-12119

22. von Gall C, Stehle JH, Weaver DR (2002) Mammalian melatonin receptors: molecular biology and signal transduction. Cell Tissue Res 309:151-162

23. Lyssenko V, Nagorny CL, Erdos MR et al (2009) Common variant in $M T N R 1 B$ associated with increased risk of type 2 diabetes and impaired early insulin secretion. Nat Genet 41:82-88

24. Nagorny CL, Sathanoori R, Voss U, Mulder H, Wierup N (2011) Distribution of melatonin receptors in murine pancreatic islets. J Pineal Res 50:412-417

25. Mussig K, Staiger H, Machicao F, Haring HU, Fritsche A (2010) Genetic variants in MTNRIB affecting insulin secretion. Ann Med 42:387-393

26. Prokopenko I, Langenberg C, Florez JC et al (2009) Variants in MTNR1B influence fasting glucose levels. Nat Genet 41:77-81

27. Bouatia-Naji N, Bonnefond A, Cavalcanti-Proenca C et al (2009) A variant near MTNR1B is associated with increased fasting plasma glucose levels and type 2 diabetes risk. Nat Genet 41:89-94

28. Simonis-Bik AM, Nijpels G, van Haeften TW et al (2010) Gene variants in the novel type 2 diabetes loci $C D C 123 / C A M K 1 D$, THADA, ADAMTS9, BCL11A, and MTNR1B affect different aspects of pancreatic beta-cell function. Diabetes 59:293-301

29. Kemp DM, Ubeda M, Habener JF (2002) Identification and functional characterization of melatonin Mel 1a receptors in pancreatic beta cells: potential role in incretin-mediated cell function by sensitization of cAMP signaling. Mol Cell Endocrinol 191:157-166

30. Bonnefond A, Clement N, Fawcett K et al (2012) Rare MTNR1B variants impairing melatonin receptor $1 \mathrm{~B}$ function contribute to type 2 diabetes. Nat Genet 44:297-301

31. Waldhauser F, Dietzel M (1985) Daily and annual rhythms in human melatonin secretion: role in puberty control. Ann N Y Acad Sci 453: 205-214 